\title{
Collaborative Environments to Support Professional Communities: A Living Lab Approach
}

\author{
Hans Schaffers ${ }^{1}$, Steffen Budweg ${ }^{2}$, Rudolf Ruland ${ }^{2}$, and Kjetil Kristensen ${ }^{1}$ \\ ${ }^{1}$ ESoCE Net, Via Cortina d'Ampezzo, 164, 00135 Roma, Italy \\ \{hschaffers, kristensen\} @esoce.net \\ ${ }^{2}$ Fraunhofer FIT, Schloss Birlinghofen, 53754 St. Augustin, Germany \\ \{steffen.budweg, rudolf.ruland\} afit.fraunhofer.de
}

\begin{abstract}
The living labs approach within ECOSPACE focuses on early user community building and active user involvement in the process of developing, testing and evaluating new collaboration concepts and tools. This paper reports about implementing and evaluating the living labs approach to facilitate innovation in collaborative work environments to enhance professional communities. The living lab approach is considered as a strategy for innovation, change and adoption. The perspective of socio-technical systems is used to understand and explain the change-catalyzing role of the living lab approach.
\end{abstract}

Keywords: Collaboration, Professionals, Living labs, Workspaces, Community.

\section{Introduction}

Collaboration across teams, organizations and communities has become normal practice. The ECOSPACE Integrated Project (www.ip-ecospace.org) explores a model of collaborative working focusing on the needs of eProfessionals. An eProfessional is a professional knowledge worker who, enabled by a variety of cooperation technologies, works together with other professionals within groups, communities and organisations in order to carry out tasks and achieve common goals. Such collaboration often starts spontaneously, for example when an expert is searching for other experts to form a team in order to develop an innovative project proposal. Often, professional workers are engaged in multiple settings of collaboration, in parallel and in different projects, and are using different collaboration platforms and tools. The complexities and difficulties that arise from such dynamic collaborative situations are targeted by ECOSPACE.

Based on current forms of eProfessional working found in practice, ECOSPACE developed detailed scenarios of eProfessional working and explored different forms of collaboration enabled by advanced ICTs. A service-oriented reference architecture was developed to guide the development and integration of collaboration tools and to focus on interoperability across the different shared workspaces of professional workers. Such interoperability is enabled by collaboration middleware and services. A portfolio of collaboration tools has been developed to facilitate creative and knowledge intensive tasks. Instant collaboration is supported by the integration of asynchronous and synchronous collaboration tools, resulting in augmented social networks and rich virtual collaboration. 
ECOSPACE launched an eProfessional living lab to experiment and evaluate innovative forms of collaborative working in three domains: media and publishing, complex projects, and professional communities of innovation. A living lab is an environment of user-driven open innovation experiments and evaluations [1]. Emphasis in this paper is on how the living lab accommodated change and adoption in the professional communities' collaboration environment.

\section{Developing the Living Lab Facility}

The ECOSPACE eProfessional living lab covers three different, distributed but interconnected experimentation settings based on the BSCW platform, a widespread webbased groupware system [2]: 1) the AMI@Work community; 2) the Frascati living lab community, and 3) the 14Plus living lab. A socio-technical systems change perspective on the collaborative work environment of professional workers allowed us to view these settings as socio-technical systems, exhibiting characteristics in terms of interactions between entities originally proposed by [3]: actors, tasks, technologies (collaborative support) and structures (organisation). This perspective provides a useful framework to understand the process of adoption and change related to information systems. In [4], a socio-technical information system change model is discussed which focuses on two types of systems: the "building system" and, a concept stemming from [5], the "work system". ECOSPACE adopted such concepts to understand the processes of change, adoption and resistance which are implied in innovation and adoption of new ways of working and new collaboration tools in professional communities. Besides the collaborative work environment system (CWE) which is evolving from the living lab innovation process, we distinguish the system of building the collaborative work environment as a separate socio-technical system in order to understand the interactions between both systems [4]. Additionally we examine the professional community system (Table 1).

Table 1. Three interacting socio-technical systems in the ECOSPACE living lab

\begin{tabular}{|l|l|l|l|l|}
\hline System & Actors & Task & Technology & Structure \\
\hline $\begin{array}{l}\text { Living lab } \\
\text { CWE system }\end{array}$ & $\begin{array}{l}\text { Users, } \\
\text { developers, } \\
\text { researchers }\end{array}$ & $\begin{array}{l}\text { Create } \\
\text { technology for } \\
\text { innovation } \\
\text { projects }\end{array}$ & $\begin{array}{l}\text { Collaboration } \\
\text { tools, services, } \\
\text { architecture }\end{array}$ & $\begin{array}{l}\text { Cyclic, spiral } \\
\text { development; } \\
\text { roadmap }\end{array}$ \\
\hline $\begin{array}{l}\text { Living lab } \\
\text { building } \\
\text { system }\end{array}$ & $\begin{array}{l}\text { Developers, } \\
\text { local } \\
\text { stakeholders }\end{array}$ & $\begin{array}{l}\text { Create } \\
\text { innovation } \\
\text { environment } \\
\text { conditions }\end{array}$ & $\begin{array}{l}\text { Living lab } \\
\text { methodologies, } \\
\text { distributed } \\
\text { infrastructure }\end{array}$ & $\begin{array}{l}\text { Stakeholder } \\
\text { communities }\end{array}$ \\
\hline $\begin{array}{l}\text { Professional } \\
\text { community } \\
\text { system }\end{array}$ & $\begin{array}{l}\text { Members of the } \\
\text { community } \\
\text { (users) }\end{array}$ & $\begin{array}{l}\text { Collaboration, } \\
\text { creating projects }\end{array}$ & $\begin{array}{l}\text { Collaborative } \\
\text { working } \\
\text { environment }\end{array}$ & $\begin{array}{l}\text { Community } \\
\text { organisation }\end{array}$ \\
\hline
\end{tabular}

We shortly introduce the three living lab settings and tools (see [1] for details). The AMI@Work community (www.ami-communities.eu) empowered by BSCW is a European-wide community of innovators active in project development with more than 3000 members. The CO-LLABS thematic network was chosen to experiment a 
series of tools meant to support thematic networks: besides the BSCW system, these included group blogging, integrated document upload and notification, multimedia conferencing, teambuilding, workspace synchronization and cross-workspace semantic querying using the SIOC Xplore widget (http://www.ami-communities.eu/wiki/ ECOSPACE/SIOC).

The Frascati living lab community is a regionally based initiative led by ESA-ESRIN (European Space Agency Centre for Earth Observation) and focuses on business incubation using technologies in the domain of space and geographical information. Besides ESA-ESRIN, it is supported by research institutes, innovation agencies, universities and small businesses. We experimented various collaboration tools aiming to support the living lab community as well as specific projects within the community, among others portal services, community blogging, integrated document upload and notification services, multimedia conferencing, expert finding and team building, and workspace synchronisation.

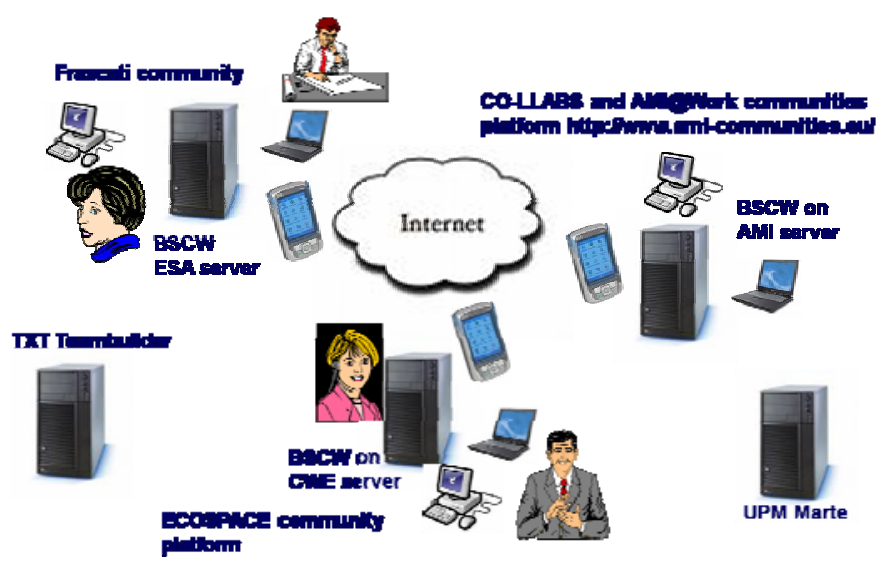

Fig. 1. Professional Communities living lab technical infrastructure

The 14Plus project supports collaboration in the German region of North RhineWestphalia between organizations promoting social and employment integration of young people above 14 years, cross-linking schools, craft industries and local community partners. A series of collaboration services have been experimented with and integrated into the BSCW system, e.g. single sign-on authentication, group blogging, tagging, portal modules with widgets, a wiki portal, and presence support.

The over-all living lab infrastructure comprises a number of different elements: the distributed networked living lab environment (Fig. 1), the local user communities which have been built up to establish user experimentation environments, methods and tools to organize, monitor and evaluate experiments, and the ECOSPACE tools development facility which creates and tests collaboration tools to be experimented in the living labs. The key approach has been to match user needs stemming from the living lab user communities and collaboration tools offered by the software partners. A tool implementation roadmap approach, adapting innovations to evolving user needs during project lifetime has been used to develop, test, introduce, train, use and 
validate the collaboration tools in the community settings. Researchers, users and developers worked together as much as possible to establish cycles of innovation.This deliberate approach might be called "action research" [6]. In itself, the launch and development of the living lab interacts with the innovation experiments carried out.

\section{Collaborative Workspace Innovations: Examples}

We experimented a series of collaboration tools in the three settings, emphasizing changing collaborative working practices. Lying at the basis of our experiments was a scenario framework proposing a set of new collaborative practices for eProfessionals. Scenarios emerged from confronting user and developer ideas, and were enriched by the experiments and user interactions, These practices include: setting up communities and providing access, sharing news and ideas, generating ideas, initiating community discussions, setting up personal workspaces, searching experts and forming teams, cross-workspace knowledge discovery and document sharing, and asynchronous and synchronous collaboration. These practices are enabled by the collaborative platform enhanced by selected and experimented services and tools. As an example we shortly present the approach and results of the 14Plus project. Table 2 presents an overview of 14Plus tool experiments and target groups during 2006-2008.

Table 2. 14Plus technology introductions

\begin{tabular}{|l|l|l|l|}
\hline \multicolumn{1}{|c|}{ Date } & Cooperation support & Base technology & \multicolumn{1}{|c|}{ Target group } \\
\hline $2006-11$ & Project workspace & BSCW platform & $\begin{array}{l}\text { Project management, } \\
\text { community members }\end{array}$ \\
\hline $2006-11$ & $\begin{array}{l}\text { Integrated Project } \\
\text { Wiki }\end{array}$ & BSCW - Wiki & $\begin{array}{l}\text { Project management, } \\
\text { community members }\end{array}$ \\
\hline $2007-03$ & Project Blog & BSCW Blog & Project management \\
\hline $2007-03$ & Presence Awareness & BSCW platform & $\begin{array}{l}\text { Project management, } \\
\text { community members }\end{array}$ \\
\hline $2007-03$ & Event Notification & RSS & $\begin{array}{l}\text { Project management, } \\
\text { community members }\end{array}$ \\
\hline $2007-06$ & Tagging & Blog \& BSCW & Project members \\
\hline $2007-10$ & Extended Logging & BSCW platform & $\begin{array}{l}\text { Living Lab building } \\
\text { system experts }\end{array}$ \\
\hline $2008-01$ & Objects visualisation & SwapIT & Project management \\
\hline $2008-04$ & $\begin{array}{l}\text { Collaborative Task } \\
\text { Management }\end{array}$ & CTM & Project management \\
\hline $2008-07$ & BSCW Presence & BSCW & Project management \\
\hline $2008-08$ & Activity Folder & BSCW & Living Lab Champions \\
\hline $2008-11$ & BSCW Widgets & $\begin{array}{l}\text { Flash/JavaScript, } \\
\text { Widget platform }\end{array}$ & Living Lab Champions \\
\hline
\end{tabular}

The setting of the 14Plus living lab is characterized by several challenges. The distribution of project partners over several locations in different regions required either intensive travel or remote communication and collaboration. Different work settings of project partners (e.g. schools, public administration, and businesses) result into 
different working times and difficulties to be available for synchronous communication. In order to cope with these challenges, the 14Plus innovation strategy followed a cyclic pattern of introductions, demonstrations, training, use and evaluations, supported by adoption and dissemination activities. Basic services were introduced first to create a support base, more complex services followed later on (the same approach has been pursued in the other settings). Table 3 presents examples of changes in the style and process of collaboration as a result of the living labs work.

Table 3. Workplace change indicators for 14Plus

\begin{tabular}{|c|c|c|c|}
\hline \multirow[t]{2}{*}{ Setting / Challenge } & \multicolumn{2}{|c|}{$\begin{array}{c}\text { Communication \& Cooperation } \\
\text { support available / used }\end{array}$} & \multirow{2}{*}{$\begin{array}{l}\text { Workplace changes / } \\
\text { improvements }\end{array}$} \\
\hline & Before Ecospace & With Ecospace support & \\
\hline $\begin{array}{l}\text { Distribution of } \\
\text { project partners over } \\
\text { several locations in } \\
\text { different regions }\end{array}$ & $\begin{array}{l}\text { Limited to use of } \\
\text { telephone, regular } \\
\text { mail, basic eMail } \\
\text { and/or intensive travel }\end{array}$ & $\begin{array}{l}\text { Adoption of CWE } \\
\text { platform and additional } \\
\text { communication } \\
\text { channels; Awareness } \\
\text { Support }\end{array}$ & $\begin{array}{l}\text { Overcoming / } \\
\text { minimizing time-space } \\
\text { barriers; efficient } \\
\text { meeting support }\end{array}$ \\
\hline $\begin{array}{l}\text { Different work- } \\
\text { settings of project } \\
\text { partners including } \\
\text { different work-times } \\
\text { and availabilities }\end{array}$ & $\begin{array}{l}\text { Asynchronous } \\
\text { communication limited } \\
\text { to traditional mail, } \\
\text { basic e-mail; No } \\
\text { support for availability } \\
\text { / presence awareness }\end{array}$ & $\begin{array}{l}\text { Additional synchronous } \\
\& \text { asynchronous } \\
\text { communication media, } \\
\text { support for handovers, } \\
\text { presence awareness; } \\
\text { flexible work-times }\end{array}$ & $\begin{array}{l}\text { Facilitation of ad-hoc } \\
\text { cooperation; lessening } \\
\text { time-space barriers; } \\
\text { support for different } \\
\text { work styles }\end{array}$ \\
\hline $\begin{array}{l}\text { Availability of Group } \\
\text { communication } \\
\text { channels }\end{array}$ & $\begin{array}{l}\text { Limited to Meetings or } \\
\text { e-mail }\end{array}$ & $\begin{array}{l}\text { Multiple Group } \\
\text { Communications } \\
\text { Channels }\end{array}$ & $\begin{array}{l}\text { Efficient \& appropriate } \\
\text { communication support; } \\
\text { Push- and Pull Media; }\end{array}$ \\
\hline $\begin{array}{l}\text { Project document } \\
\text { repository with } \\
\text { remote access for all } \\
\text { members }\end{array}$ & Not available & $\begin{array}{l}\text { Integrated CWE and } \\
\text { project workspace }\end{array}$ & $\begin{array}{l}\text { Access from distributed } \\
\text { work places to main } \\
\text { materials for work }\end{array}$ \\
\hline
\end{tabular}

The successful adoption and appropriation of new technology support introduced to support the project's innovation capability required careful interplay between the different systems and stakeholders involved. Two examples can illustrate the related co-evolution: First, within the initial three months of the introduction of the baseline CWE workspace and collaboration platform, more than 450 documents were created. This change resulted in new requirements and needs towards the living lab technology for maintaining structure and overview of the large project repository, iteratively leading to the development and introduction of increased support for awareness and change monitoring. Secondly, new members joining the network during the later evolution of the project increased the need for guidance and starting points for the long evolved cooperation structure. Both social and technical measures were implemented, including the establishment of local facilitators and champions serving as guides as well as the extension of the project's wiki system offering new users a specific entry point. With the wiki becoming an alternate starting point, widgets were then introduced to include presence and awareness support from the baseline system to support end-users with an integrated view.

We experimented the required integration of multiple technological systems in different ways, including the development of an interface to share workspaces across 
two CWE systems (BSCW and Business Collaborator; BC), by using the related concepts of Shadow Folder and Semantic Folder. Our scenario for this approach was as follows. Two companies collaborate: Turners Photography Studio, a photography company; uses the BC platform, and Baker Publication Design, a publications company that specializes in designing brochures; uses the BSCW platform. These two companies have been commissioned to produce a brochure, entitled European Cities. The photographers of Turners travel to Prague, Valencia, Rome, and Paris, taking photos and uploading them to a BC folder as they go. This BC Folder is connected as a Shadow Folder to the BCSW system of Baker. Via the Shadow Folder, Baker's publisher can access the photos and incorporate them immediately into the brochure. For a final review, the brochure is uploaded to a BSCW folder, which is connected as a Semantic Folder in Turners BC system. Here, the photographers may view the finished prototype, and representatives from both organisations can work in their own CWE, improving usability and efficiency. Additionally, we have been exploring a CWE interoperability architecture, based on SIOC (Semantically-Interlinked Online Communities), providing a middleware to enable multiple, independent CWE platforms and third-party applications to share and correlate data (Fig. 2).

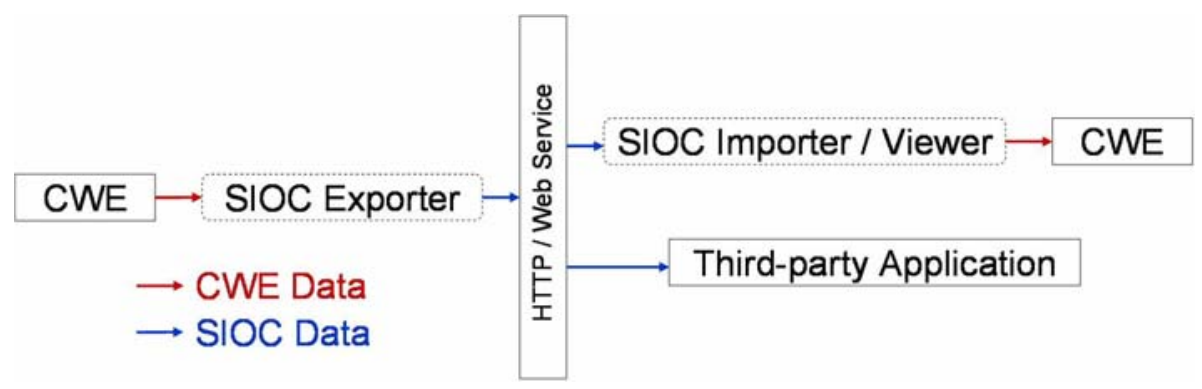

Fig. 2. Interoperability architecture

Firstly CWE data is exported as SIOC data. Then the SIOC data is imported by other CWEs or by third-party applications. Finally the SIOC data is utilized accordingly, including e.g. 1) SIOC Exporter; based on conceptual mapping, SIOC exporters translate platform-specific data into SIOC RDF data, 2) Workspace Synchronization Web Service; the workspace synchronization web service exposes the content of a CWE workspace as SIOC data to external systems. CWE items (documents, folders) may then be accessed, added, deleted, renamed, or replaced remotely via these services, and 3) SIOC Importer/Viewer; Importing remote SIOC data into a CWE allows a user to view data from a remote SIOC RDF source as if it was a local folder in the CWE. The SIOC Importer/Viewer reverts the SIOC data into CWE platform-specific data, based on conceptual mapping.

\section{Living Lab Innovation and Workplace Change}

Living labs are mechanisms for socio-technical systems change. ECOSPACE pursues the view of living labs as innovation projects, resulting in concrete innovations. 
Whereas this is a valid and practical view, which might become clear from the examples presented in section 3, there is more to living labs. Living lab actors including researchers, users, developers and stakeholders engage in social relationships. To fulfil its potential, the living lab as an innovation system should be balanced with the system of initiating and building the living lab conditions, and with the dynamically changing characteristics of the wider professional community which is involved in living labs innovation. All three systems could potentially reinforce each other to support the development of a broad, self-sustainable innovation facility. We interpret our findings and results in terms of three interacting socio-technical systems as in Table 1: the living lab building system, the CWE innovation system, and the professional community system. Fig. 3 summarizes the interactions.

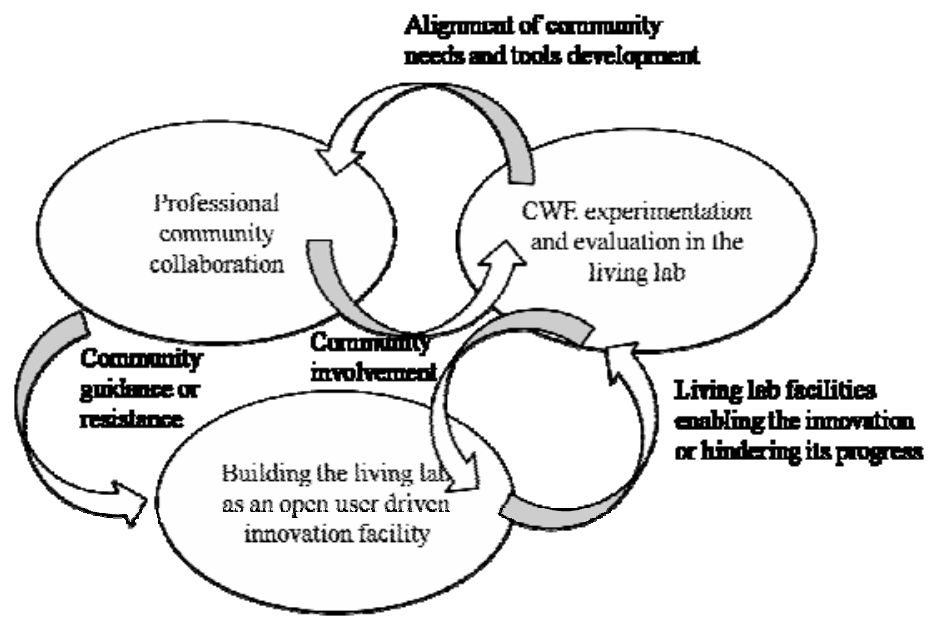

Fig. 3. The living lab as socio-technical system of learning and adaptation

The living lab building system is a dominant activity in the beginning of the project. However it strongly interacts with the professional community system, as community guidance and actually "ownership" is required in order to avoid negligence or even active resistance. The CWE innovation system in which the professional community normally should participate, regularly progresses through phases of preparation, limited prototyping and experimentation, wider scale experimentation and evaluation, and full-scale co-creation. Alignment of tools proposed by software developers and requested in the living lab is a critical process. Only if this alignment succeeds - which is essentially a human interaction process, conditioned by trust there will be a basis for appropriation of the tools in the actual workplace. The professional community system evolves in close relation to the innovations in the CWE innovation system.

\section{Conclusions}

Our research shows that careful co-development of the living lab system, the CWE innovation system and the professional community system is required for living labs 
to fulfil the role as successful self-sustainable innovation facilities. In particular, the interplay and interfaces between these three systems must be carefully managed.

Change issues in socio-technological systems also play an important role in many facets of living lab related technology development and deployment, especially within the development models and processes (e.g. software design methodologies), change management during the development processes (e.g. management of requirements and releases) as well as the flexibility of the technological systems and tools provided (e.g. customisation and appropriation flexibility). Technology development within Living Lab activities brings multiple challenges, such as balancing openness and closure of the development process over time, balancing requirements and functionality implementation between local demands and broader target audiences, and balancing as-early-as-possible continuous user involvement and real-life usage with the required level of maturity for new tools released for productive use.

Ceating successful innovations in an open community setting is a complex undertaking that requires careful coordination of a number of different stakeholders and roles across the innovation lifecycle: Clear responsibilities and ownership is a critical success factor, and the level of ambition should be coherent with the resources available to avoid further fragmentation and situations where initiated activities are not completed, undermining the reputation of living labs as a systemic approach. Without clear leadership and proper clarification of ownership of the required support activities, there is a risk that valuable initiatives fail because phase-specific activities critical for the outcomes are missing or executed with poor quality.

\section{References}

1. Schaffers, H., Budweg, S., Kristensen, K., Ruland, R.: A living lab for enhancing collaboration in professional communities. Submitted to the ICE 2009 conference, Leiden (2009)

2. Appelt, W.: WWW based collaboration with the BSCW system. In: Pavelka, J., Tel, J., Bartosek, M. (eds.) SOFSEM 1999. LNCS, vol. 1725, p. 66. Springer, Heidelberg (1999)

3. Leavitt, H.J.: Applied organization change in industry: structural, technical and human approaches. In: March, J.G. (ed.) Handbook of Organizations, Chicago, Rand McNally, pp. 55-71 (1965)

4. Lyytinen, K., Newman, M.: Explaining information systems change: a punctuated sociotechnical change model. European Journal of Information Systems 17, 589-613 (2008)

5. Alter, S.: The work system method for understanding information systems and information systems research. Communications of the Association for Information Systems 9, 90-104 (2002)

6. Baskerville, R.: Investigating information systems with action research, Communications of the Association for Information Systems 2, Article 19 (1999),

http: //cais.isworld.org 